\title{
Estudo virtual em tempos de distanciamento: uma análise sobre o impacto do isolamento social na rotina de estudos de universitários
}

\author{
Daniela D. S. Bagatini ${ }^{1}$, Rodrigo O. Soares ${ }^{2}$, Eriko Bruno C. Barros ${ }^{3}$, Francisco \\ Gustavo S. Correia ${ }^{4}$
}

${ }^{1}$ Departamento de Engenharias, Arquitetura e Computação da Universidade de Santa Cruz do Sul (UNISC) - Santa Cruz do Sul - RS - Brasil

1,2Programa de Pós-Graduação em Informática na Educação da Universidade Federal do Rio Grande do Sul (UFRGS) - Porto Alegre - RS - Brasil

${ }^{3}$ Departamento de Medicina da Universidade Federal do Maranhão (UFMA), Campus Pinheiro - Pinheiro - MA - Brasil

${ }^{4}$ Departamento de Saúde Pública da Universidade Federal do Ceará (UFC) - Fortaleza CE - Brasil

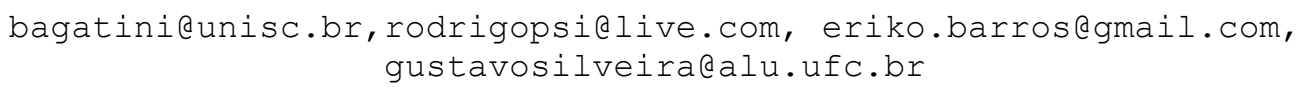

\begin{abstract}
This article talks about engagement when it comes to the recommendations of social isolation and the implications perceived in the study routine based on college students perspectives. Through the elaboration and application of a questionnaire, this paper discuss aspects such as Agreement, Engagement, Impact, Satisfaction, Time, Workload, Anxiety, Sadness and discouragement, Technologies Support and achievement and experience. As a result, it concluded that the students from the sample feel committed and agree to follow the recommendations of social isolation. Finally, their routine of study is impacted by: dedicated time, worry and anxiety, feelings of sadness and discouragement.
\end{abstract}

Resumo. Este artigo trata do engajamento com as recomendações de isolamento social e as implicações percebidas na rotina de estudos a partir do olhar dos universitários. Através da elaboração e aplicação de um questionário, buscou-se discutir aspectos como Concordância, Engajamento, Impacto, Satisfação, Tempo, Carga de trabalho, Ansiedade, Tristeza e desânimo, Apoio das tecnologias e Aproveitamento e experiência. Como resultado, concluiu-se que os estudantes da amostra se sentem comprometidos e concordam em seguir as recomendações de isolamento social. Por fim, na rotina de estudos impactam: tempo dedicado, preocupação e ansiedade, sentimentos de tristeza e desânimo.

\section{Introdução}

Em dezembro de 2019 um surto repentino de pneumonia viral assolou a cidade de Wuhan, China, deixando as autoridades sanitárias internacionais em alerta. A Organização Mundial de Saúde (OMS) denominou a doença como coronavirus 2019 - "COVID-19" - e declarou o status pandêmico da infecção em 11 de Março de 2020. A disseminação do vírus e transmissão da doença ocorre devido ao contato próximo com pessoa infectada e à 
exposição à tosse, espirros ou gotículas respiratórias dispersas em suspensão no ar em forma de aerossóis, e.g. Li et al. (2020). Segundo Van Doremalen et al. (2020), o contato com superfícies contaminadas também constitui meio importante de disseminação da infecção.

$\mathrm{O}$ avanço no número de infectados e a rapidez com que o vírus se espalhou globalmente gerou uma crise em saúde sem precedentes. Estratégias de quarentena estão sendo impostas em diversos países em uma tentativa de conter a propagação da infecção por COVID-19, incluindo a recomendação de isolamento, toque de recolher voluntário em casa, restrição à reunião de grupos de pessoas, cancelamento de eventos sociais e públicos planejados, fechamento de sistemas de transporte de massa, escolas e universidades, comércio e restrições de viagem, e.g. Usher, Bhullar e Jackson (2020). De acordo com Brooks et al. (2020), as restrições impostas por consequência do surto de COVID-19 têm causado perturbações significativas em todo o mundo e a indivíduos, famílias, comunidades e países inteiros.

Isolamento social e quarentena são experiências frequentemente desagradáveis para aqueles que são submetidos a tais medidas: separação dos entes queridos, a perda de liberdade, incerteza sobre o status da doença, implicações financeiras e tédio podem, ocasionalmente, gerar impactos psicológicos e emocionais difíceis de reverter. As alterações drásticas recentemente vividas alteram o que é familiar e complicam aspectos da vida cotidiana que antes eram simples e descomplicados. A suspensão de uma rotina estável pode afetar diversas esferas, como no caso do contexto educacional, que se deparou com uma demanda irrevogável de adaptações de modo a tornar possível o andamento de suas atividades, atenuando minimamente o impacto já causado na atual conjuntura.

A temática do uso das tecnologias entre universitários já recebe a nossa atenção desde épocas anteriores ao isolamento (Soares et al., 2018). Desse modo, é natural o nosso interesse em investigar como o estudante entende a sua rotina de estudos a partir do uso destas tecnologias em tempos de isolamento social. Para isto, realizamos um levantamento de trabalhos correlacionados através do método de bibliometria quantitativa e qualitativa. No decorrer do artigo, apresentamos os procedimentos metodológicos e análise dos dados coletados.

O trabalho de Wolfers et al. (2020) discute a relação entre estresse e a nomofobia (medo de ficar sem celular/smartphone), bem como o estresse e uso das mídias sociais. Os resultados apontam que maior nomofobia foi associada a um maior nível de estresse, enquanto o uso passivo do Facebook estava associado a um maior nível de estresse para os participantes mais jovens da amostra. Cabe aqui retomar os resultados obtidos por Brooks et al. (2020) ao destacar o estresse como um efeito negativo - agora em um contexto de isolamento social imposto. Wolfers et al. (2020) ainda comentam que intervenções focadas no uso problemático das mídias devem ser adaptadas ao público-alvo e ir além de simplesmente tentar reduzir o tempo de uso. Portanto, salientam que é preciso abordar a maneira como a mídia digital é usada, chamando atenção para a indispensabilidade de caminhos investigativos que possam tratar das condições de um uso bem-sucedido de dispositivos de mídia.

Rich (2013) traz um discurso coerente com o dos autores anteriores ao alertar que corremos o risco de ficar estagnados em posicionamentos polarizados, defendendo não ser mais possível manter a abordagem da definição da tecnologia do nosso tempo como algo bom ou ruim, buscando alternativas para aproveitar esses avanços de maneira consciente e 
focada. Amparados por Wolfers (2020), no que concerne às condições de uso das tecnologias, e com base na perspectiva de Rich (2013), acreditamos que para entender o impacto das condições de um uso bem-sucedido é necessário compreender as experiências dos usuários quanto à abordagem utilizada.

A partir de uma análise de utilização das mídias/tecnologias no contexto educacional, o trabalho de Olasina (2019) chama atenção para os fatores humanos e sociais que afetam a decisão dos estudantes em aceitar o e-learning. Alerta para o fato de que as tecnologias educacionais colaboram com o desenvolvimento acadêmico apenas quando são amplamente aceitas e usadas. Os resultados sugerem que fatores como estresse, carga de trabalho, satisfação, fadiga e gerenciamento de tempo, causam impacto na decisão de aceitar o e-learning. Tais fatores são influenciados pelas dimensões culturais, humanas e sociais, além da utilidade percebida do recurso e da pressão de colegas e professores. Dados os resultados apresentados por Olasina (2019), entendemos que questões humanas e sociais, no cenário atual de isolamento e enfrentamento da COVID-19, têm impacto no engajamento e na prática dos estudantes em sua rotina de estudos e em sua relação com os recursos tecnológicos.

\section{Metodologia}

A pesquisa consistiu em analisar o estudo virtual em tempos de isolamento social com o propósito de entender como a situação atual da pandemia tem impactado na rotina de estudos dos universitários do ensino presencial. Para nortear a investigação, estabelecemos as seguintes questões: (1) Como o estudante entende o seu engajamento com as recomendações de isolamento social? e (2) Quais as implicações percebidas para a sua rotina de estudos?

Para este fim, utilizamos um questionário que contém 10 itens, elaborados a partir do olhar interdisciplinar dos autores e com embasamento do referencial teórico apresentado na seção 1. O questionário foi desenvolvido no Google Forms e sua divulgação feita por convite, por intermédio do Diretório Acadêmico dos Cursos de Computação, a estudantes de uma Universidade do sul do país. O questionário ficou disponível de 28 de Abril a 21 de Maio de 2020. Após esta data, os dados foram estruturados em formato $\operatorname{csv}$ e submetidos à análise estatística e a mineração de textos.

\subsection{Procedimentos}

O questionário foi organizado em três momentos: (1) apresentação da pesquisa e orientação; (2) oito questões fechadas, e (3) duas questões abertas.

No momento de apresentação da pesquisa e orientação, foi ressaltada a participação de forma voluntária e anônima, visto que nenhum dado sobre nome e e-mail seria coletado. Também, informamos ao participante sobre a importância de responder ao questionário da maneira mais sincera possível pensando sobre a situação atual de isolamento social. A preocupação com a ética na pesquisa foi ressaltada antes de iniciar o segundo momento, quando esclarecido que, ao seguir respondendo o questionário, o participante consentia a utilização do conteúdo para a pesquisa, embora a qualquer momento este poderia se recusar a responder o questionário ou desistir de participar e retirar seu consentimento sem nenhum prejuízo. No momento das questões fechadas, o participante respondeu a oito perguntas, compostas por opções de resposta organizadas numa escala likert de 1 a 4 . O Quadro 1 
IX Congresso Brasileiro de Informática na Educação (CBIE 2020)

Anais do XXXI Simpósio Brasileiro de Informática na Educação (SBIE 2020)

apresenta os aspectos trabalhados para cada uma das oito questões e suas opções de respostas. Foi solicitado ao participante que escolhesse apenas uma opção.

\begin{tabular}{|c|c|c|}
\hline Aspectos & Perguntas & Opções \\
\hline Concordância & $\begin{array}{l}\text { P1. Você concorda com as recomendações de } \\
\text { isolamento social (toque de recolher voluntário } \\
\text { em casa, restrição à reunião de grupos de } \\
\text { pessoas, cancelamento de eventos sociais, } \\
\text { fechamento de sistemas de transporte de massa, } \\
\text { escolas, comércio e restrições de viagem)? }\end{array}$ & $\begin{array}{l}\text { (1) Não concordo; (2) Concordo } \\
\text { parcialmente; (3) Concordo; (4) } \\
\text { Concordo plenamente. }\end{array}$ \\
\hline Engajamento & $\begin{array}{l}\text { P2. Você se sente comprometido em seguir as } \\
\text { recomendações de isolamento social? }\end{array}$ & $\begin{array}{l}\text { (1) Não me sinto comprometido; (2) } \\
\text { Parcialmente comprometido; (3) } \\
\text { Comprometido; (4) Totalmente } \\
\text { comprometido. }\end{array}$ \\
\hline Impacto & $\begin{array}{l}\text { P3. De que forma ter aulas integralmente a } \\
\text { distância têm impactado na sua rotina atual de } \\
\text { estudos? }\end{array}$ & $\begin{array}{l}\text { (1) Não tem sido impactante; (2) } \\
\text { Pouco impactante; (3) Impactante; (4) } \\
\text { Muito impactante. }\end{array}$ \\
\hline Satisfação & $\begin{array}{l}\text { P4. Qual seu grau de satisfação com a sua rotina } \\
\text { atual de estudos? }\end{array}$ & $\begin{array}{l}\text { (1) Não estou satisfeito; (2) Pouco } \\
\text { satisfeito; (3) Satisfeito; (4) Muito } \\
\text { satisfeito. }\end{array}$ \\
\hline Tempo & $\begin{array}{l}\text { P5. Você acredita que o tempo que dedica à sua } \\
\text { rotina atual de estudos: }\end{array}$ & $\begin{array}{l}\text { (1) Não é adequado; (2) É pouco } \\
\text { adequado; (3) É adequado; (4) É } \\
\text { muito adequado. }\end{array}$ \\
\hline $\begin{array}{l}\text { Carga de } \\
\text { trabalho }\end{array}$ & $\begin{array}{l}\text { P6. De que forma fatores como carga de } \\
\text { trabalho e fadiga têm impactado na sua rotina } \\
\text { atual de estudos? }\end{array}$ & $\begin{array}{l}\text { (1) Não tem sido impactante; (2) } \\
\text { Pouco impactante; (3) Impactante; (4) } \\
\text { Muito impactante. }\end{array}$ \\
\hline Ansiedade & $\begin{array}{l}\text { P7. Na sua rotina atual, com que frequência } \\
\text { você se sente preocupado ou ansioso? }\end{array}$ & $\begin{array}{l}\text { (1) Nunca; (2) Às vezes; (3) } \\
\text { Frequentemente; (4) Sempre. }\end{array}$ \\
\hline $\begin{array}{l}\text { Tristeza e } \\
\text { desânimo }\end{array}$ & $\begin{array}{l}\text { P8. Nas últimas semanas, com que frequência } \\
\text { você se sente triste ou desanimado? }\end{array}$ & $\begin{array}{l}\text { (1) Nunca; (2) Às vezes; (3) } \\
\text { Frequentemente; (4) Sempre. }\end{array}$ \\
\hline
\end{tabular}

Quadro 1. Aspectos e questões objetivas.

Os aspectos Concordância e Engajamento permitem identificar a compreensão do participante quanto ao processo de isolamento social. Já, os aspectos Impacto e Satisfação, visam verificar a avaliação do participante com a rotina de estudos. Através dos aspectos Tempo e Carga de trabalho é possível perceber o impacto do tempo disponível para o cumprimento das demandas. Os aspectos Ansiedade e Tristeza e desânimo identificam a frequência com a qual os participantes se deparam com estes sentimentos na rotina de estudos. O Quadro 2 apresenta as questões abertas.

\begin{tabular}{|l|l|}
\hline Aspectos & Perguntas \\
\hline $\begin{array}{l}\text { Apoio das } \\
\text { tecnologias }\end{array}$ & $\begin{array}{l}\text { P9. Nas últimas semanas, quais tecnologias você percebe que realmente têm apoiado } \\
\text { os seus estudos e desenvolvimento acadêmico? Comente sobre a sua experiência. }\end{array}$ \\
\hline $\begin{array}{l}\text { Aproveitamento } \\
\text { e experiência }\end{array}$ & $\begin{array}{l}\text { P10. De que forma a situação de isolamento social tem impactado no aproveitamento } \\
\text { da sua rotina atual de estudos? Conte-nos um pouco sobre a sua experiência. }\end{array}$ \\
\hline
\end{tabular}

\section{Quadro 2. Aspectos e questões abertas.}

As perguntas abertas, como aspectos Apoio das tecnologias e Aproveitamento e experiência, tratam do suporte oferecido pelas tecnologias, assim como os efeitos que o contexto de isolamento tem trazido para a rotina de estudos dos participantes. De forma a garantir uma resposta com maior riqueza de detalhes, os participantes deveriam responder no mínimo 120 caracteres. 


\subsection{Análise dos dados}

Foi realizada uma análise descritiva dos dados quantitativos e uma análise bivariada dos domínios (utilizando o teste exato de Fisher). As análises foram realizadas no Stata (versão 16). Já para os dados qualitativos das questões abertas, a partir da ferramenta de mineração textual Sobek (http://sobek.ufrgs.br/), foram identificadas palavras-chave dos textos dos participantes e gerados grafos que permitiram realizar a análise das respostas textuais.

\subsection{Participantes}

A coleta contou com 38 participantes, estudantes dos Cursos de Computação de uma Universidade do sul do país. Todas as questões foram respondidas, visto que eram de preenchimento obrigatório, mesmo as questões abertas.

\section{Resultados}

Esta seção descreve os resultados obtidos a partir das questões fechadas (Perguntas 1 a 8) e abertas (Perguntas 9 e 10).

\subsection{Questões fechadas}

Os resultados descritivos, encontrados sobre o aspecto Concordância (Figura 1a), indicam que $52,6 \%$ (20) das respostas, manifestam que os estudantes concordam plenamente com as recomendações de isolamento social; $28,9 \%$ (11) concordam parcialmente; $18,4 \%$ (7) concordam; e, nenhum estudante indica não concordar. Já para o aspecto Engajamento (Figura 1b), as respostas mostram que 34,2\% (13) se sentem comprometidos em seguir as recomendações de isolamento social; 26,3\% (10) manifestam estar totalmente comprometidos; $21,1 \%$ (8) indicam estar parcialmente comprometidos; e, $18,4 \%$ (7) informam não se sentirem comprometidos.

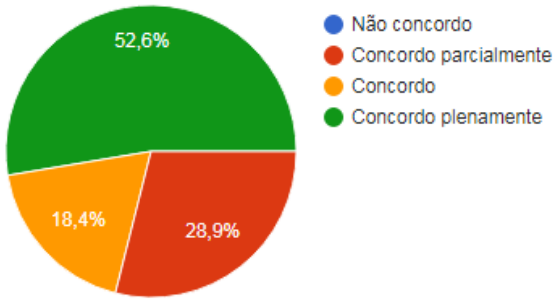

(a) Concordância

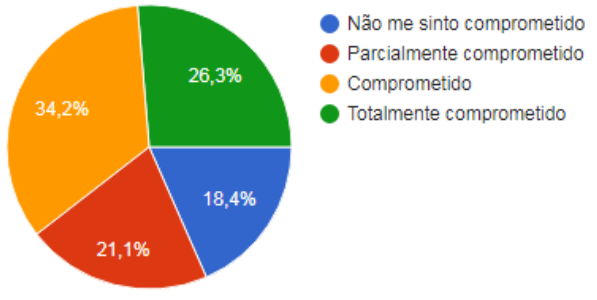

(b) Engajamento

Figura 1. Aspectos Concordância e Engajamento.

Quanto ao aspecto Impacto, as respostas dos estudantes indicam que 39,5\% (15) consideram que o fato de ter aulas integralmente a distância é pouco impactante na rotina atual de estudos; 31,6\% (12) manifestam ser impactante; $18,4 \%$ (7) relatam ser muito impactante; e, 10,5\% (4) assinalam não ser impactante. No que tange ao aspecto Satisfação (Figura 2b), 42,1\% (16) apontam estar satisfeitos com a sua rotina atual de estudos; 34,2\% (13) revelam estar pouco satisfeitos; $15,8 \%$ (6) mencionam não estar satisfeitos; e, 7,9\% (3) informam estar muito satisfeitos.

Sobre o aspecto Tempo, indicam que 39,5\% (15) das respostas dos estudantes consideram ser pouco adequado o tempo que dedicam à rotina atual de estudos; $31,6 \%(12)$ manifestam ser adequado; 21,1\% (8) indicam não ser adequado; e, 7,9\% (3) indicam ser muito adequado. Para o aspecto Carga de trabalho (Figura 3b), 36,8\% (14) apontam que 
fatores como carga de trabalho e fadiga são pouco impactantes na rotina atual de estudo; $34,2 \%$ (13) mencionam ser impactantes $15,8 \%$ (6) mencionam ser muito impactantes; e, $13,2 \%$ (5) assinalam não ser impactantes.

Por fim, sobre o aspecto Ansiedade, as respostas dos estudantes indicam que 36,8\% (14) manifestam que, considerando a rotina atual, com que frequência se sentem preocupados ou ansiosos; $28,9 \%$ (11) revelam que sempre; $21,1 \%(8)$ indicam que às vezes; e, 13,2\% (5) dizem que nunca se sente, preocupados ou ansiosos. Já para o aspecto Tristeza e desânimo (Figura 4b), 31,6\% (12) manifestam que, nas últimas semanas, com que frequência se sentem tristes ou desanimados; $28,9 \%$ (11) mencionam às vezes; $21,1 \%$ (8) sinalizam que nunca; e, $18,4 \%$ (7) revelam que sempre se sentem tristes ou desanimados.

Com vistas a aprofundar a explicação sobre os aspectos analisados, observamos a associação do conjunto de elementos através da análise de duas variáveis qualitativas, com o intuito de esboçar indícios em direção a considerações acerca do processo de estudo virtual em tempos de isolamento social. $\mathrm{Na}$ análise bivariada, ao comparar os domínios mais próximos, identificamos uma relação estatisticamente significante entre Tristeza e desânimo e Ansiedade ( $\mathrm{p}$-valor $=0.000$ ).

Tabela 1. Distribuição da Ansiedade pela Tristeza e desânimo.

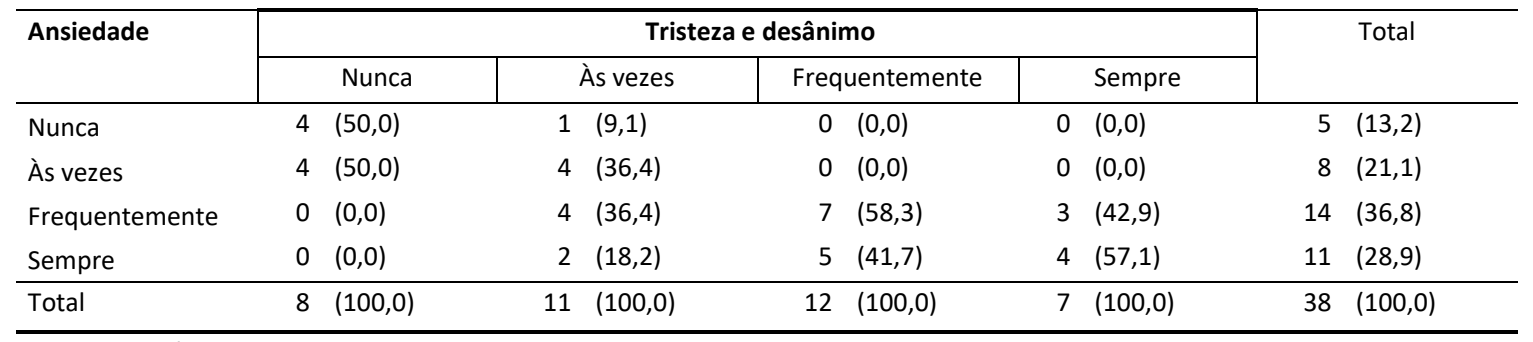

NOTA: Fisher's exact $=0.000$

Os números entre parênteses são percentagens em relação aos totais das colunas.

Ao analisar a relação entre domínios não próximos, encontramos uma associação estatisticamente significante entre Satisfação e Tempo ( $\mathrm{p}$-valor $=0.016)$.

Tabela 2. Distribuição da Satisfação pelo Tempo.

\begin{tabular}{|c|c|c|c|c|c|c|}
\hline \multirow[t]{2}{*}{ Satisfação } & \multicolumn{4}{|c|}{ Tempo } & \multirow{2}{*}{\multicolumn{2}{|c|}{ Total }} \\
\hline & Não é adequado & É pouco adequado & É adequado & É muito adequado & & \\
\hline Não estou satisfeito & $3 \quad(37,5)$ & $3 \quad(20,0)$ & $0 \quad(0,0)$ & $0 \quad(0,0)$ & 8 & $(21,1)$ \\
\hline Satisfeito & $1(12,5)$ & $8(53,3)$ & $7 \quad(58,3)$ & $0 \quad(0,0)$ & 12 & $(31,6)$ \\
\hline Muito satisfeito & $0 \quad(0,0)$ & $0 \quad(0,0)$ & $1(8,3)$ & $2(66,7)$ & 3 & $(7,9)$ \\
\hline
\end{tabular}

NOTA: Fisher's exact $=0.016$

Os números entre parênteses são percentagens em relação aos totais das colunas.

Sendo de nosso interesse avaliar o aspecto Engajamento em relação com outros domínios, criamos duas classes de respostas: (1) engajados (que responderam Comprometido ou Totalmente comprometido); (2) não engajados (que responderam Não me sinto comprometido ou Parcialmente comprometido). A partir da pergunta "Há diferenças entre alunos engajados e não engajados com relação aos outros domínios?", encontramos para a classe engajados, relações estatisticamente significantes entre domínios: Impacto e Satisfação $(\mathrm{p}=0.01)$, Impacto e Carga de trabalho $(\mathrm{p}=0.00)$, Satisfação e Ansiedade $(p=0.03)$, Tempo e Tristeza e desânimo $(p=0.04)$, Carga de 
trabalho e Tristeza e desânimo $(\mathrm{p}=0.04)$, Ansiedade e Tristeza e desânimo $(\mathrm{p}=0.01)$. Para a classe não engajados, encontramos apenas a relação entre Carga de trabalho e Ansiedade $(p=0.00)$, portanto entre os não engajados, há uma estreita relação estatística entre Carga de trabalho e Ansiedade $(\mathrm{p}=0.00)$.

\subsection{Questões abertas}

Para auxiliar a compreensão textual das respostas obtidas nas questões discursivas, optamos por utilizar uma ferramenta de mineração textual chamada Sobek. A ferramenta identifica os termos considerados mais relevantes de um texto (ou conjunto de textos, neste caso) baseada na frequência com que eles aparecem e na sequência os apresenta em forma de grafo, tornando possível analisar de forma fácil e rápida os termos que aparecem com maior recorrência nas respostas dadas pelos alunos do estudo. Para isto, foram selecionadas todas as respostas para as perguntas 9 e10, conforme apresentado na Tabela 1.

Os grafos foram gerados separadamente, de modo que fosse possível analisar os termos mais recorrentes no grupo de respostas dadas para cada questão e as ligações existentes entre estes termos. $\mathrm{Na}$ questão número 9 as palavras mais recorrentes foram Google, aulas e Youtube. A palavra mais recorrente, Google (5), apareceu constantemente ligada à também citada Youtube, assistir as aulas e ferramentas, denotando que a página e seus respectivos recursos eram fonte principal de apoio no que concerne ao desenvolvimento acadêmico e de suporte aos alunos entrevistados. A Figura 2 apresenta o primeiro grafo de mineração textual gerado pelo Sobek.

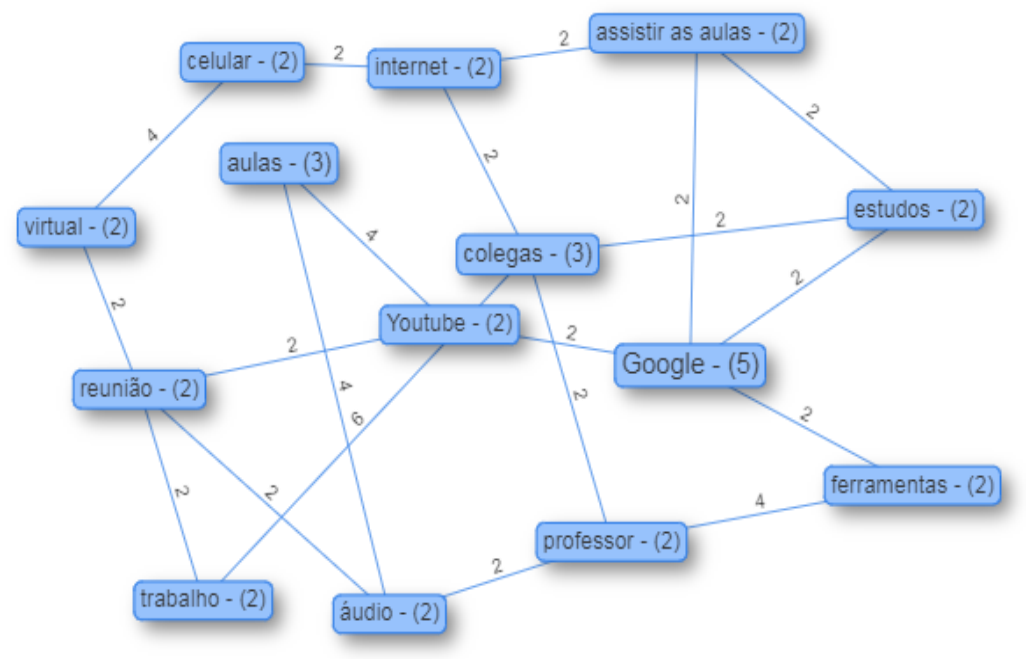

Figura 2. Mineração de textos da Pergunta 9.

$\mathrm{Na}$ questão número 10 as palavras mais recorrentes foram tempo, casa, rotina e tarefas (Figura 3). A palavra mais recorrente, tempo (17), aparece relacionada a trabalhos, isolamento, atividades e casa. Observamos durante a análise que as menções sobre o tempo tratavam dos desafios de conciliá-lo com outros compromissos além dos acadêmicos (família, trabalho, etc.). A Figura 3 apresenta o segundo grafo de mineração textual gerado pelo Sobek. 


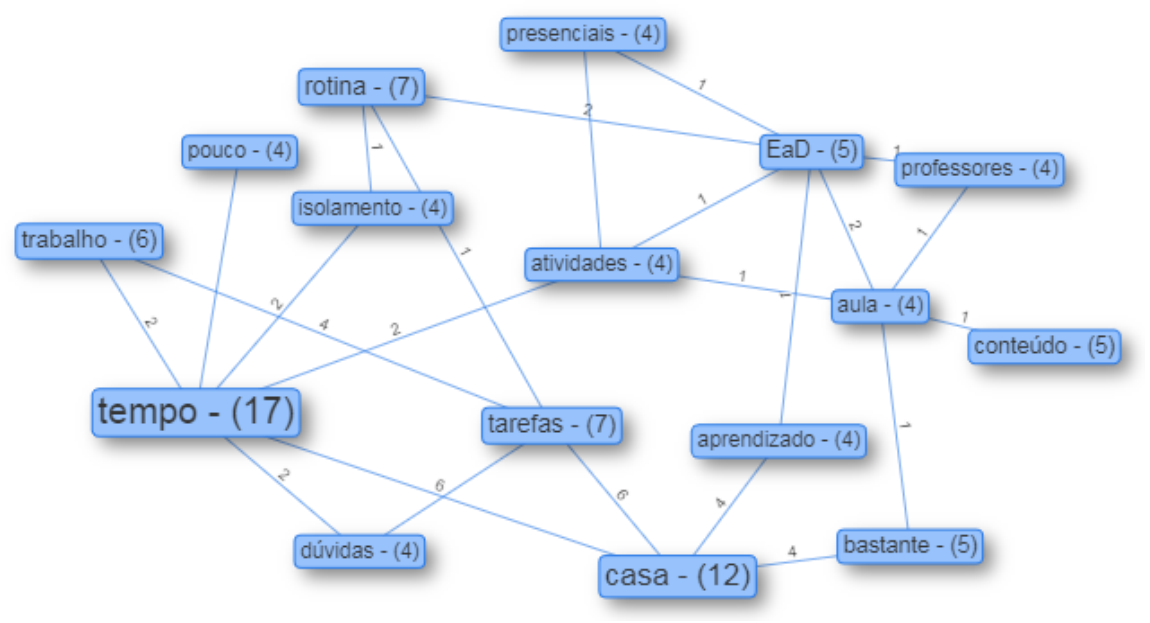

Figura 3. Mineração de textos da Pergunta 10.

Nesta seção foram apresentados os dados obtidos a partir das questões fechadas (Perguntas 1 a 8) e abertas (Perguntas 9 e 10). Na seção 4 faremos a discussão destes resultados.

\section{Discussão dos resultados}

Com base nos dados da análise descritiva podemos perceber que os estudantes estão de acordo com as recomendações ( $71,1 \%$ concordam ou concordam plenamente) e, também, engajados $(60,5 \%$ comprometidos ou totalmente comprometidos) em seguir as recomendações de isolamento social. Apesar deste resultado indicar concordância, nas questões que abordavam os tópicos Satisfação e Carga de Trabalho, tem-se uma proporcionalidade entre as opções de respostas dos estudantes, visto que parte se declara satisfeita com a rotina de estudos atual (50\%) e outra não. De igual forma, parte aponta que a carga de trabalho é impactante nesta rotina (50\%) e outra não, assim como os resultados sobre o aspecto Impacto das aulas à distância na rotina, que também apresentam o mesmo percentual. Por outro lado, os estudantes consideram que o tempo dedicado aos estudos é pouco ou não é adequado $(60,5 \%)$. Ainda verificamos que, com frequência, os participantes se sentem preocupados ou ansiosos $(65,7 \%)$. Por fim, metade das respostas manifestam que com frequência, ou sempre, $(50 \%)$ os estudantes se sentem tristes ou desanimados.

Ao observar a associação em conjunto dos aspectos, em razão da relação estatística significante, podemos inferir que há uma relação entre o grau de preocupação e ansiedade e a frequência com que os participantes se sentem tristes ou desanimados. Também identificamos que quanto maior o grau de satisfação com a rotina atual de estudos, maior o nível de adequação do tempo dedicado a esta rotina. Os resultados da análise bivariada dos domínios indicam que os estudantes com um comprometimento maior às recomendações de isolamento social (engajados), apresentam maior envolvimento com as mudanças ocorridas durante a pandemia. Entendemos que os estudantes percebem como o isolamento social teve impacto na sua rotina de estudos, principalmente no que tange aos aspectos da organização do tempo, preocupação e ansiedade, e isto é potencialmente mais significativo para aqueles que se mostraram mais engajados.

Já em nossa análise dos grafos gerados pelo Sobek para as perguntas abertas, observamos que o Google se destaca como tecnologia de apoio ao processo de estudos. As ferramentas do Google, como o Meet, aparecem como estratégias de compensação diante 
IX Congresso Brasileiro de Informática na Educação (CBIE 2020)

Anais do XXXI Simpósio Brasileiro de Informática na Educação (SBIE 2020)

da impossibilidade do trabalho presencial e fonte principal de pesquisa, conforme apresentado nos excertos a seguir:

O Google meet para a comunicação, o Whatsapp também, e claro que o aprofundamento com os materiais que os professores disponibilizam. Além do sites para as pesquisas e materiais de apoio.

Google Meet, porque permite que tenhamos contato direto e imediato com professores e colegas e possibilita melhor uso das ferramentas tecnológicas.

Observamos que, no contexto do isolamento social, o tempo se apresenta como fator impactante no aproveitamento da rotina de estudos. Porém, as respostas manifestam experiências diferentes. Para alguns, aparece como fator positivo, pois evidenciam o estudo como compromisso principal ou exclusivo. Já para outros, como mais um desafio diante da conciliação do tempo dedicado aos estudos, trabalho e família.

[...] tem contribuido positivamente para meus estudos em geral, pois tenho muito tempo livre para dormir, ter entretenimento e então poder estudar com muito mais entusiasmo e eficiência.

[...] como trabalho, sobra pouco tempo para estudo. A falta de um professor na minha frente para ser tirado dúvidas, que muitas vezes surgem na resolução dos problemas, tem sido muito prejudicial.

Por estar trabalhando 8 h30 em home office, [...] às vezes acabo optando por realizar as tarefas da faculdade de madrugada para poder descansar depois do trabalho.

Julgamos necessário destacar que a natureza dos dados coletados não nos possibilita comprovar se este fator - seja ele positivo ou negativo - tem relação com os recursos que os participantes utilizam para a realização dos estudos de forma remota. Esta temática pode ser analisada com maior profundidade em estudos futuros.

Ao traçar uma relação entre os resultados observados nas análises estatísticas e na mineração dos textos, ressaltamos que o último grafo não destaca palavras relacionadas à preocupação e ansiedade, ou ainda, sentimentos de tristeza e desânimo. Isto implica no não aparecimento destas respostas em virtude de sua baixa frequência. Salientamos, contudo, que estes sentimentos aparecem diluídos em diferentes maneiras de manifestar uma insatisfação semelhante. Cabe aqui lembrar que os relatos sobre ansiedade referentes à rotina dos estudantes, manifestam-se através de escolhas variadas de palavras (desanimada, ansiosa, sobrecarregada, estou "preso" em casa, afetou o convívio, muitas vezes você fica remando sem sair do lugar).

\section{Conclusão}

Através de um olhar para o contexto atual da COVID-19, surgiu o interesse em investigar como o estudante universitário entende o seu processo de estudo em tempos de isolamento social, a partir da sua organização e de aspectos que podem impactar na sua rotina. Para nortear a pesquisa, estabelecemos e respondemos as seguintes questões:

(1) Como o estudante entende o seu engajamento com as recomendações de isolamento social? Os estudantes estão engajados, portanto se sentem comprometidos e concordam em seguir as recomendações de isolamento social. No grupo dos engajados, identificamos resultados estatísticos que evidenciam que estes percebem de forma mais intensa os impactos do isolamento na rotina atual. 
(2) Quais as implicações percebidas para a sua rotina de estudos? Os estudantes manifestam que o tempo é um fator de impacto na satisfação com a rotina e que isto influencia no aproveitamento dos estudos. Para alguns surge como fator positivo e para outros como mais um desafio dentre tantas outras demandas. Também afeta na rotina a preocupação e ansiedade, sentimentos de tristeza e desânimo.

Ressaltamos a importância de novos estudos que permitam a continuação e aprofundamento dos dados obtidos por esta pesquisa, bem como a ampliação da base de dados para análise e a discussão longitudinal dos resultados, tanto dos aspectos relacionados às questões fechadas, quanto das questões abertas. Por fim, pode ser interessante identificar se os recursos utilizados pelos estudantes impactam nos aspectos discutidos nesta pesquisa.

\section{Referências}

Brooks, S. K. et al. (2020) The psychological impact of quarantine and how to reduce it: rapid review of the evidence. In: The Lancet, v.395, n.10227, March 14, p.912-20. Disponível em: $<$ https://doi.org/10.1016/S0140-6736(20)30460-8>. Acesso em: jul. de 2020.

Li, Q. et al. (2020) Early Transmission Dynamics in Wuhan, China, of Novel CoronavirusInfected Pneumonia. In: The New England journal of medicine, v.382, n.13, p.1199-1207.

Olasina, G. (2019) Human and social factors affecting the decision of students to accept elearning. In: Interactive Learning Environments, 03 April, v.27(3), pp.363-376. Disponível em: $<$ https://doi.org/10.1080/10494820.2018.1474233>. Acesso em: jul. de 2020.

OMS. (2020) Folha informativa - COVID-19 (doença causada pelo novo coronavírus). Atualizada em 13 de abril. Disponível em: $<$ https://www.paho.org/bra/index.php?option=com_content\&view=article\&id=6101:covid19 \&Itemid=875>. Acesso em: jul. de 2020.

Rich, M. (2013) As mídias e seus efeitos na saúde e no desenvolvimento de crianças e adolescentes: reestruturando a questão da era digital. Em: C. N. Abreu, E. Eisenstein e S. G. B. Estefenon (Orgs). In: Vivendo esse mundo digital: impactos na saúde, na educação e nos comportamentos sociais. Porto Alegre: Artmed.

Soares, R. O.; Bagatini, D. D. S.; Reategui, E. B.; Biasuz, M. C. V.; Zaffaroni, F. (2018) Uso da Internet por Estudantes Universitários: um Campo de Estudo Emergencial. In: Revista Novas Tecnologias na Educação (RENOTE), v.17, p.1-11.

Usher, K.; Bhullar, N.; Jackson, D. (2020) Life in the pandemic: Social isolation and mental health. In: Journal of clinical nursing. Disponível em: $<$ http://www.ncbi.nlm.nih.gov/pubmed/32250493>. Acesso em: jul. de 2020.

Van Doremalen, N. et al. (2020) Aerosol and Surface Stability of SARS-CoV-2 as Compared with SARS-CoV-1. In: New England Journal of Medicine, 17 mar. Disponível em: $<$ https://doi.org/10.1056/NEJMc2004973>. Acesso em: jul. de 2020.

Wolfers, L. N.; Festl, R.; Utz, S. (2020) Do smartphones and social network sites become more important when experiencing stress? Results from longitudinal data. In: Computers in Human Behavior, v.109, March, p.1-11, Disponível em: <https://doi.org/10.1016/j.chb.2020.106339>. Acesso em: jul. de 2020. 